\title{
Reform-Based Science Teaching: Teachers' Instructional Practices and Conceptions
}

\author{
Moshe Barak and Larisa Shakhman \\ Ben-Gurion University of the Negev, Beer Sheva, ISRAEL
}

This study aimed at exploring the practices and beliefs physics teachers have about introducing reform-based instruction into the physics class. Data were collected from semi-structured interviews held with 11 experienced physics teachers. The results revealed that the teachers occasionally introduced a small number of enhanced instructional strategies explicitly required by the formal curriculum into their class, such as presenting, analyzing and generalizing experimental results in different forms. However, the teachers used much fewer other strategies aimed at enhancing higher-order thinking, such as asking students to formulate their own questions or introducing them to problem-solving strategies used in class. Although physics is considered a relatively well-established subject in Israeli schools, extensive differences have been identified among teachers in issues such as using rich instructional strategies in class, their self-confidence in utilizing progressive instruction, and their beliefs about students' abilities to develop higher-order thinking. Teachers often regard reform-based instruction as an idealistic view rather than a clear schooling practice; further work is required in teachers' pre-service and in-service training to make the fostering of higher-order thinking a common ingredient in science teaching.

Keywords: Higher-Order Thinking, Instructional Strategies, Perceptions, Science Teaching

\section{INTRODUCTION}

A major goal of science education today is fostering students' intellectual competencies, such as independent learning, problem-solving, decision-making and critical thinking (American Association for the Advancement of Science (AAAS), 1994; National Research Council (NRC), 1996). It is widely agreed that in order to achieve this end, science teaching must be shifted from traditional schooling to more constructivist-oriented instruction. Schraw, Crippen and Hartlely (2006) stress the obligation of science education to foster student's meta-cognition and self-regulation, and mention six strategic areas essential for achieving this goal: (a)

Correspondence to: Moshe Barak, Dr. Science Education, Department of Science and Technology Education,

Ben-Gurion University of the Negev,

Beer Sheva 84105, Israel

E-mail:mbarak@bgu.ac.il inquiry-based learning; (b) the role of collaborative support; (c) strategy instruction to improve problemsolving and critical thinking; (d) strategies for helping students to construct mental models and experience conceptual change; (e) the use of technology; and (f) the impact of students' and teachers' beliefs.

Over the past few decades, these ideas about the objectives and methods of science education have prevailed within the community of science educators. However, the change instigated at the school level has been very slow, and most studies today still take place using routine methods, i.e., the teacher delivers content or the students algorithmically solve many exercises. There is almost unanimous agreement that in order to foster students' higher-level thinking, teachers must possess not only in-depth subject matter knowledge in the field they are specializing in, such as mathematics, physics or biology, but also good pedagogical knowledge on how to develop students' higher-order thinking in the context of the subject matter they are dealing with (Brickhouse, 1990; Bybee, 1993; Fullan, 
1993; Kagan, 1992; Hollon et al., 1991; Pajares, 1992; Richardson, 1996). Moreover, it is increasingly being recognized that the ability of teachers to reflect on their instruction is very consistent with their capability to plan, execute and improve instruction aimed at fostering higher cognitive processes in class (Leou, 2006). Zohar (2006) stresses that in order to support students' learning in reforms that highlight inquiry and thinking, teachers require "sophisticated knowledge that cannot be embedded in curriculum materials or scripted into instructional routines."

In Israel, considerable efforts have been made to promote the professional development of science teachers in areas such as biology (Zohar, 2004a, 2004b), chemistry (Hofstein et. al., 2004) and physics (Yerushalmi and Eylon, 2004). Yet, relatively little is known about what teachers working in regular schools believe or do about promoting students' thinking skills by teaching science, and to what extent they see themselves committed to this goal. Consequently, the general purpose of this study was to investigate teachers' practices regarding the promotion of higher-order thinking in teaching the required curriculum and to understand their beliefs about reform-based schooling.

\section{THEORETICAL FRAMEWORK}

Dancy and Henderson (2007) claim that although terms such as reform, change and improvement are frequently used in the dialog on science education, these terms are not clearly defined and no consensus exists as to their exact meaning. These authors suggest a comprehensive framework for articulating reform-based science education, consisting of two parts. The first part relates to educational Practices, namely teachers' behaviors regarding 1) Interactivity, 2) Instructional decisions, 3) Knowledge source, 4) Students success, 5) Learning mode, 6) Motivation, 7) Assessment, 8) Content, 9) Instructional design and 10) Problem-solving. Regarding the aspect of Instructional decisions, for example, while a reformoriented science teacher shares decisions with his/her students, a conservative teacher decides exclusively on his/her own. Regarding the aspect of Content, alternative instruction means that a teacher explicitly teaches students how to learn, think and solve problems, in addition to teaching scientific content; in contrast, a teacher in a traditional class deals mainly with facts and principles.

The second part of the framework mentioned above describes teachers' Conceptions, namely attitudes, goals and other similar types of mental behavior regarding science education. This part relates to teachers' views on 1) Learning , 2) Expertise, 3) Knowledge, 4) Nature of science, 5) Role of school, 6) Students 7) Teacher's role, 8) Diversity, 9) Desired outcomes, and 10) Scientific Literacy. In the aspect entitled Role of school, for example, while teachers holding alternative educational beliefs regard school as a place to help students develop as independent thinkers and enrich their personal lives, educators holding traditional views of education often regard school as a place to prepare students for their future roles in the workplace and society.

The distinction between teachers' Practices and Conceptions, as Dancy and Henderson (2007) suggest, is valid and useful, because a teacher might hold very progressive views about education, but in practice use conservative teaching methods; such a situation could be a result of various factors such as a teacher's lack of content or pedagogical knowledge, difficulties in adapting to change, or pressure at school. We will discuss this point in more detail later in the paper.

\section{Teaching higher-order thinking in the science class}

Questions like what constitutes good thinking or how to foster students' thinking in school in general, and in science lessons in particular, have been increasingly discussed in the educational literature over the past few decades (Beyer, 1988; Costa, 1985; Glaser, 1984; Pogrow, 1988; Sternberg, 1987; Zohar, 1999, 2004a; Zohar and Dori, 2003). Resnick (1987) suggested the concept of 'higher-order thinking,' which avoids a precise definition of thinking but instead points towards some general characteristics of higher-level thinking, as follows: higher-order thinking is non-algorithmic, complex, yields multiple solutions, requires the application of multiple criteria, self-regulation, and often involves uncertainty. According to the National Science Teachers Association (NSTA, 2003, p.18), "the ability to engage in effective inquiry using scientifically defensible methods is considered a hallmark of scientific literacy... Inquiry is characterized by a degree of uncertainty about outcomes... True inquiry ends with an elaboration and judgment that depends upon the previous reasoning processes." In accordance with the Benchmarks for Scientific Literacy (American Association for the Advancement of Science (AAAS), 1994) and the National Science Education Standards (National Research Council (NRC), 1996), authors like Zoller (1997) and Zohar and Dori (2003) include the following examples of higher-order thinking patterns in inquiryoriented science education: formulating a research question, planning experiments, controlling variables, drawing inferences, making and justifying arguments, identifying hidden assumptions, and identifying reliable sources of information.

Swartz (2001) points out that during the late 1980s and throughout the 1990 s, teachers in a wide variety of schools all over the United States, as well as in other countries, restructured the ways they teach common content to infuse instruction in diverse thinking skills. 
Costa (2002) mentions two advantages of infusing the teaching of thinking skills into teaching science. First, skillful thinking cannot be performed in a vacuum there must be something to think about. Second, the nature of scientific inquiry imposes certain constraints on problem-solving processes; scientific problems, in which the control of experimental variables is paramount, differ from social and aesthetic problems in which ethics and artistic judgment play a significant role. Swartz and Parks (1994) suggested four basic components that should be included in designing the teaching of problem-solving strategies in the science class: 1) explicitly Introducing a thinking strategy to the students in the context learning of the subject matter; 2) actively Engaging the students in the suggested strategy; 3) Reflection on the strategy after gaining some experience in using it; and 4) Teaching for Transfer, namely showing the students how the specific strategy can be used in other related situations. Figure 1 illustrates this model.

So far we have seen the potential of science education as a platform for developing students' thinking skills. Unfortunately, science studies are often dictated by a rigid syllabus or the obligation to prepare students for various types of tests, such as regional and national surveys or final high school exams. In Israel, for example, high school students must take matriculation exams ('Bagrut') in all subjects learned in high school. Since getting high scores in these exams is a key criterion for enrolling into higher education, particularly in areas such as engineering or medicine, most of the teachers and students focus their efforts on learning towards these exams. Indeed, the required curriculum demands that students be able to deal with non-routine questions and tasks both in theoretical studies and lab work. Yet, questions exist as to how teachers address the task of fostering students' thinking skills in science class. Since, as we noted earlier, both teachers' beliefs and behaviors play an important role in the educational process, in this study we aimed at exploring questions such as: What are teachers' conceptions about reform-based instruction versus traditional teaching of science? What teaching methods are actually used in science class using these two contrary methods?

The significance of this study lies in its potential to contribute to the literature and to educational practice related to teacher training, with special focus on instruction aimed at promoting higher cognitive processes in the classroom.

\section{METHOD}

\section{Context of the study and the participants}

The study involved the participation of 11 physics teachers, eight females and three males, most of them having over 10 years of experience in the teaching profession. Each participant taught physics in a different school; all of the schools were located in or close to a central city in the southern part of the country. Although these schools serve a heterogeneous population - from students living in affluent neighborhoods to students coming from relatively lowincome families, physics students are quite a homogeneous group within these schools because they all learn the same curriculum and take the same official matriculation exams. The gaps between students in different schools cannot be extreme, because in Israel, as in many other countries, physics is frequently regarded as a subject aimed only at high-achieving students, an 'elite' subject in science studies (Angel et al., 2004; Osborne et al., 1998; Woolnought, 1994). We don't claim to have taken a random sample; instead, we selected the participating teachers to represent fairly well the profile of experienced physics teachers countrywide. A similar approach was adopted, for example, by Dancy and Henderson (2005), who explored the barriers in using researched-based instructional strategies in teaching physics by conducting semi-structured interviews with five well-respected, tenured physics faculty members from different institutions. In our study as well, most of the teachers were regarded as important figures in their schools, often in charge of preparing the physics class for the matriculation exam. Huberman (1989) described teachers having this type of background as being in the 'divergent period' of their professional development, characterizing them as follows: "Some teachers describe this as a period of experimentation and activism as they develop their own courses, try out new approaches to teaching, and confront institutional barriers. Yet, others see it as a period of self-doubt and reassessment; many teachers leave the profession at this stage as their level of frustration with the system reaches its peak."

We are aware of the limits of basing the study on a relatively small sample; however, we see an advantage in focusing the study on teachers from a specific discipline, in particular a relatively well-established field like physics, and from schools located within a relatively small geographical area. This enables concentrating the discussion on the knowledge and attitudes of teachers having a common professional background while reducing the influence of factors related to the differences between the disciplines or the diversity of the population served by the schools. It is also worth mentioning that the study addressed the teachers during their regular work throughout the school year, rather than under special circumstances, such as teaching a new curriculum or participating in an in-service course. Therefore, we believe that the context of the study described above contributed to the validity of the outcomes. 


\section{Data collection and analysis}

The study adopted the qualitative methodology aimed at obtaining a holistic understanding of the participants' viewpoints on the issue of higher-order thinking in teaching physics, how they understand this concept, and what stays beyond their external expression of their behavior (Silverman, 1997). To this end, the main data collection method involved holding semi-structured interviews with the teachers individually in their schools. The principal value of interviews (Fontana and Frey, 2000; Silverman, 1993) is that they offer a rich source of data that provides access to how people account for their understandings and attitudes about everyday experiences.

The interviews, which lasted about 90 minutes, started out by presenting the teacher with a list of 22 strategies often used in teaching physics, such as formulating a research question, controlling variables, or drawing inferences from an experiment. These instructional strategies were selected from the current literature on physics education and materials used in teachers' courses in Israel (Yerushalmi and Eylon, 2004; Van Heuvelen, 1991). We chose to start the conversation in this way in order to create a convenient opening discussion during the interview. The interviewees were asked to comment on each strategy, for example, the extent he/she uses it in class, its advantages and disadvantages, or where he/she had learned it. The interviewees were also encouraged to add additional strategies they knew or used. The conversation, however, did not adhere to this format but rather developed into divergent directions according to each teacher's interests or preferences. Similar to the study Henderson and Dancy (2005) conducted, the participants were asked about their instructional goals, current and past instructional teaching experience, or attempts to make changes. The interviewer, the second author of this article, has herself been a physics teacher for about 15 years. To create a relaxed atmosphere, the interview started with an explanation to the interviewee that the study is about teaching physics in general, and that there is no intention to evaluate him/her in any way. The fact that the study is based primarily on what the teachers said without an attempt to evaluate the teachers in their practical work in the class is limiting on the one hand, but also advantageous on the other; since the interviewees were not in any position of being judged or at risk in any way, they could reflect freely on their teaching and honestly express their views. We believe that this approach encouraged the teachers to talk about their successes and their failures, rather than attempting to present themselves at their best.

The interviews were recorded and transcribed verbatim. An inductive analysis was performed (Patton, 1990) in which patterns, themes and categories of analysis were extracted from the data. First, we reread the transcripts separately to formulate a tentative understanding; in subsequent readings, we attempted to confirm this understanding. As part of the verification methodology (Strauss, 1987), we repeatedly reread the data; initial categories were revised following several rounds of discussion.

\section{FINDINGS}

In the Findings section, we refer to teachers' practices and beliefs regarding reform-based instruction, their views about students' abilities to acquire higherorder thinking, and the participants' reflections on their own abilities to teach higher-order thinking.

\section{Teachers' use of reform-oriented instructional strategies}

As previously noted, one of the main means used by teachers to enhance cognitive processes in class is applying diverse instructional strategies. At the beginning of the conversation, the interviewer showed the teacher a list of 22 strategies to enhance science learning and suggested that they talk about these strategies. The teachers were asked, for example, if they could indicate to what extent they use each strategy in their class on a four-level scale (never / seldom / often / very often), or express their opinions about the effectiveness of the various methods. The interviewees were also encouraged to cite additional strategies they knew or used. However, this was just a starting point for the discussion, which developed in divergent directions according to each teacher's interests or preferences, as detailed later in the paper.

The mean frequencies the teachers attributed to using each strategy are listed in descending order in Table 1.

It can be seen that among the strategies marked by the teachers as being the most useful in teaching physics were (ranked 1-4): generalization of physical concepts based on experimental results; teaching diverse problem-solving methods; guiding students systematically to justify their solutions to a problem or their decisions; and presenting data in diverse forms, i.e., graphs, tables or texts. These results, as illustrated in Figure 2, are not surprising because the skills mentioned above are required either in formal paper-and-pencil exams or lab exams. It should be noted, however, that most of the teachers often refer to the term 'problemsolving' as solving standard computation exercises. In contrast, the teachers marked instructional strategies (ranked 19 and 20 in Table 1), such as asking students to formulate their own questions or learning through teamwork, as being much less important. It is also worth mentioning that the teachers marked moderate 
use of strategies related to fostering reflection (between "often" and "seldom"), such as explicitly discussing thinking strategies used in class with the students, or asking the students to state the difficulties they encountered and explain how they resolved them.

Beyond the discussion of the specific 22 instructional strategies mentioned above, only two or three of the 11 teachers who participated in this study cited the development of students' thinking skills as being a major objective in teaching physics or presented examples of how they were actively attempting to achieve this goal. One of these teachers said the following:

"I don't allow them to answer quickly because if I do, they won't have time to think. First I force them to think: I don't accept any answer for about two minutes, for example... the answer must be the result of the thinking process, and thinking requires time."

Another teacher said:

"A student asks a question and I ask three... in the beginning, they are in shock, and I explain: never mind, I want to understand correctly what you are asking, to find out the answer from you, because sometimes after three questions you already know it by yourselves."

These examples illustrate cases in which the teachers regard students' thinking as an important issue in itself. However, this was not the common situation. More often, teachers consider problem-solving strategies as a matter of efficient learning. The following comments reflecting this perspective were noted in the interviews:

"[Thinking strategies] are not methods for solving a specific question but are rather organizational methods; if you are well organized, you don't waste time and can concentrate on the subject matter."

Or:

"[Efficient] working methods avoid redundant work and add to understanding the content."

Another view expressed by the teachers was that problem-solving strategies are intended to raise students' confidence. The following quote demonstrates this point:

"I prepare a lot of charts for them [how to solve a question]: Do this in this case, do that in another case... what to do first and what later... The students love having strategies. They do not

Table 1: Teacher's use of instructional strategies aimed at fostering higher-order thinking in physics $(\mathrm{n}=11)$.

\begin{tabular}{|c|c|c|}
\hline Rank & Strategy & $\begin{array}{l}\text { Mean } \\
\text { Frequency* }\end{array}$ \\
\hline 1 & Presenting data in diverse forms, i.e. graphs, tables or texts & 2.91 \\
\hline 2 & Guiding students systematically to justify their solutions to a problem or their decisions & 2.73 \\
\hline 3 & Teaching diverse problem-solving methods & 2.45 \\
\hline 4 & Generalizations based on experimental results & 2.45 \\
\hline 5 & Asking for students explanations' before teachers' explanations & 2.36 \\
\hline 6 & Stating the strong and weak points of different solutions to a problem & 2.27 \\
\hline 7 & Linking what is learned in physics class to other scientific fields & 2.27 \\
\hline 8 & $\begin{array}{l}\text { Predicting the results of an experiment or a theoretical solution to a problem and providing } \\
\text { justifications }\end{array}$ & 2.18 \\
\hline 9 & Asking students to verbally present the thinking stages they used in solving a problem & 1.91 \\
\hline 10 & Guiding students to add their own examples & 1.91 \\
\hline 11 & $\begin{array}{l}\text { Presenting conflicts: facts or examples that conflict with students' previous knowledge and } \\
\text { intuitions }\end{array}$ & 1.82 \\
\hline 12 & Discussions of questions to which the answers are vague & 1.73 \\
\hline 13 & Allotting time for thinking in the class & 1.73 \\
\hline 14 & Asking students to state the difficulties they encountered and explain how they resolved them & 1.64 \\
\hline 15 & $\begin{array}{l}\text { Discussions with students regarding the thinking strategies used in class, such as making } \\
\text { decisions, asking questions }\end{array}$ & 1.45 \\
\hline 16 & $\begin{array}{l}\text { Creating situations whereby the students present contradicting positions and try to convince one } \\
\text { other }\end{array}$ & 1.36 \\
\hline 17 & Encouraging students to participate in scientific contests and projects & 1.27 \\
\hline 18 & Guiding students to present diverse viewpoints around a particular issue & 1.18 \\
\hline 19 & Asking students to formulate their own questions & 1.09 \\
\hline 20 & Learning through teamwork in the class & 1.09 \\
\hline 21 & Use of concepts maps & 1.09 \\
\hline 22 & Involving students in determining evaluation criteria & 0.34 \\
\hline
\end{tabular}


always know how to use them but they feel more confident if they think they have strategies..."

A third reason mentioned by the teachers for trying to use various instructional approaches was that the matriculation exams are a requirement of the formal curriculum. Some teachers stated this explicitly, as seen in the examples below:

"Any additional word [verbal explanation for a computation exercise] in the matriculation exam is a plus for them... what will students do in the exam if they are unable to justify their answers?"

One teacher mentioned that the generalization of scientific concepts is also a matter of studying for the exam:

"[In a theoretical lesson] we present the results of a lab experiment and make a generalization... this has recently become a requirement... In the matriculation exam, the results of an experiment are presented and the student must draw conclusions from them."

In their efforts to 'help' their students instead of challenging them, the teachers quoted above tried to save the students the hard work of thinking.

\section{Teachers' arguments for conservative teaching}

While teachers' explanations as to how or why they use a specific teaching strategy refer mainly to educational practices, the reasons they give for maintaining conventional teaching give us a very good idea about their perceptions of reform-based science education. Beyond the common claims that the obligation to convey mandatory content does not allow enough time for more progressive instruction, the teachers mentioned other reasons for continuing to use traditional teaching. Two interviewees perceived the development of thinking as an issue separate from the teaching of physics, and suggested providing students with special courses to foster thinking skills. One teacher said the following:

"It is necessary to include the learning of logic in the curriculum. This is important."

Other teachers believed that the mere teaching of physics develops students' thinking, as the following quotes show:

"Nothing develops thinking like physics... for example graphs...this is abstract thinking... it requires concentration... solving problems... understanding concepts like energy conversion."

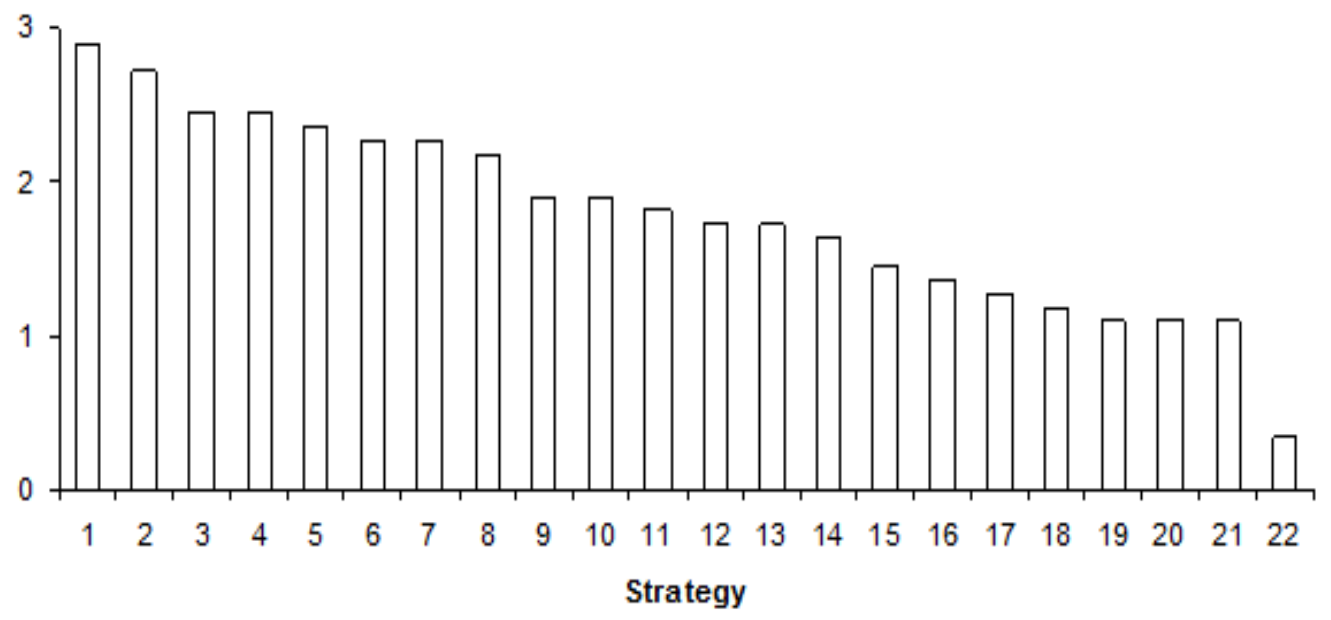

Figure 1: A four-stage model for the infusion of instructional strategies aimed at fostering thinking skills into teaching subject matter.

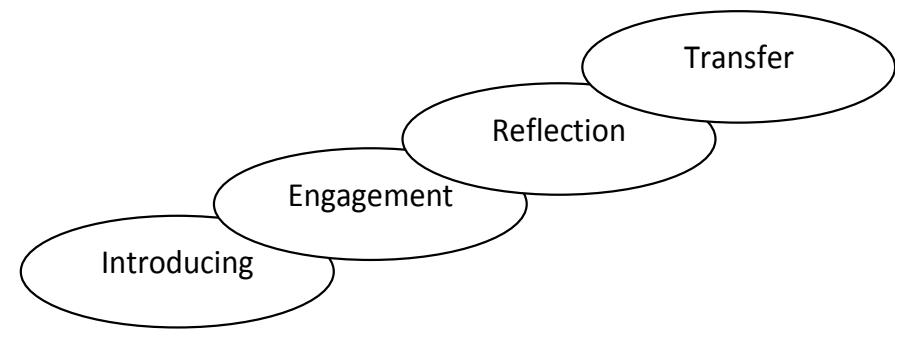

Figure 2: Teacher's use of instructional strategies 
Or:

"It's easier to develop thinking in physics because you have the tools to do so. What are the tools of thinking? You have a collection of principles and rules... you use them to solve a problem or a conflict... therefore this discipline, physics, helps to develop thinking."

Since, as we have already mentioned, physics is commonly regarded as a difficult subject, when teachers in the current study talked about fostering thinking by teaching the subject matter, they probably took into account students having relatively strong scholastic backgrounds.

Another argument used by the teachers in their preference for conventional teaching was that the intensive delivery of subject matter is necessary in order to control the class:

"In today's situation, if you stop [teaching] you lose control over the class... the students start talking."

Or:

"If I had a quiet class I could hold more discussions. In our school, discipline is a problem. In a class that has discipline problems, all you can do is to teach technically."

And also:

"Since the students lack the culture of discussion, it is difficult. They start shouting at one another and so it is a waste of time."

Three teachers specifically stated that they felt insecure in using compound instructional strategies, as illustrated below:

"I don't like discussions... I don't know where they lead and I don't have the tools to deal with this later. In discussions, they [the students] sometimes exaggerate, so then what do I do?"

'Teachers' beliefs about students' abilities in acquiring higher-order thinking

Certainly, teachers' beliefs about students' understanding, thinking and learning are critical factors in any educational reform (Kagan, 1992; Pajares, 1992). The conversations with the teachers indicated that the interviewees were divided into two extreme poles regarding their estimation of students' potential to acquire higher-order thinking. At one pole were four 'pessimistic' teachers who said things like:

"In the tests, I wish they knew [at least] one way to solve a problem, my poor students."

And
"Man was born the way he was... maybe it is possible to teach him to think a little bit but not too much. A creature that was born to crawl will not be able to fly. It is possible to improve, but if you study physics you must know how to both think and sit."

At the other pole were five teachers who had great confidence in their students, as expressed in the examples below:

"If you keep telling them 'you have to decide,' 'you decide for yourselves,' they get used to the notion that they also have a say in class."

And also:

"They are more intelligent than I am, but perhaps lazier; I always say that 'if I had their brains I would have gone a lot farther'."

The optimistic teachers frequently talk about the potential of their students to succeed but at the same time mention their own duty to support and encourage them. Since students majoring in physics are usually selected carefully in each school, the large gaps found in teachers' viewpoints about the students cannot refer exclusively to the students' scholastic backgrounds but must also deal with the teachers' beliefs. We will discuss this point in more detail later in the paper.

\section{Do teachers' perceptions about their students relate to their self-esteem about teaching higher-order thinking?}

So far we have examined separately teachers' reflections about their abilities to teach higher-order thinking and their views about students' abilities in acquiring higher-order thinking. We find it interesting to explore to what extent teachers' perspectives on these issues inter-correlate; if a strong correlation exists, it could hint that the teachers relate their selfesteem to how they assess their students ' abilities.

To this end, we classified the teachers according to the viewpoints they expressed in the interviews regarding two aspects mentioned above on a simple scale of strong (explicit positive position), moderate (indecisive) or weak (low perception), as illustrated in Table 2. Although we recognize that this type of grading is not very accurate, it can help in the current discussion.

Table 2 shows that teachers' estimations about their students' abilities in handling reform-oriented learning only partially match their self-esteem about using progressive instructional methods in class: three teachers (T8, T10, T11) expressed a low position in both aspects; three other teachers (T2, T3, T4) had strong viewpoints; three teachers (T5, T6, T7) had higher perceptions about the students than their selfconfidence in teaching higher-order thinking; only two 
Table 2. Mapping the 11 teachers (T1-T11) according to their self-evaluation in using higherorder instructional strategies and their views about their students

\begin{tabular}{|c|c|c|c|c|}
\hline \multirow{3}{*}{ 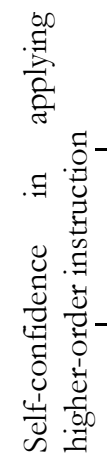 } & 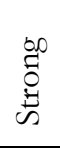 & T9 & T1 & $\begin{array}{l}\text { T2, T3, } \\
\text { T4 }\end{array}$ \\
\hline & 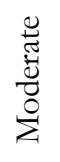 & & & T5 \\
\hline & 节 & T8, T10, T11 & $\mathrm{T} 7$ & T6 \\
\hline & & Weak & Moderate & Strong \\
\hline & & \multicolumn{3}{|c|}{$\begin{array}{l}\text { Belief in students' abilities to acquire } \\
\text { higher-order thinking }\end{array}$} \\
\hline
\end{tabular}

teachers (T1, T9) had stronger self-esteem than their evaluation of the students. Since, as mentioned earlier, students majoring in physics in high school are normally considered to be a relatively excellent group in their schools, and the teachers in this study were also experienced in their profession, it is likely that the above findings indicate a type of confusion among the teachers regarding the use of reform-guided instruction of physics in their classes.

\section{SUMMATIVE DISCUSSION}

This study aimed at exploring the practices and beliefs that physics teachers have about introducing reform-based instruction into their class. Although all the participants in this study were experienced teachers, and the fact that physics is considered to be a welldeveloped field in Israeli schools, extensive differences have been identified among the teachers in issues such as the use of rich instructional strategies in the class, their self-confidence in utilizing progressive instruction, and their beliefs about their students' abilities to develop higher-order thinking. These findings exhibit some parallel lines with a similar study (Dancy and Henderson, 2005; Henderson and Dancy, 2005) in which the researchers conducted semi-structured interviews with five senior, well-respected physics faculty members who made significant efforts in their teaching. Although these instructors held beliefs about teaching, learning and instructional goals that are largely consistent with reform-based education, it was found that their self-described instructional practices were largely traditional. Dancy and Henderson (2005) mention several common systematic forces that that are likely to impede the implementation of research- informed practices, such as students' resistance, time structure, department norms, expectation of content coverage and lack of instructor time. Some of these forces are also relevant in teaching science in the Israeli system, in which the major factor affecting instruction in high school is the matriculation exams taken by the students. Therefore, despite the fact that the constructivist view of learning has been placed at the center of teachers' pre-service and in-service programs for at least two decades, teachers often regard reformbased instruction as an idealistic view of education rather than a clear schooling practice. The significant diversity of the teachers, as well as the cases in which the teachers highly evaluate their students but show moderate or low self-confidence in their own abilities to teach higher-order thinking, indicate that many teachers are confused or embarrassed about reform-based instruction. Further work is therefore required in teachers' pre-service and in-service training to make the fostering of higher-order thinking a common ingredient in science teaching.

To get closer to introducing advanced instruction into the science class, we adopt Pogrow's (1996) approach that educational change requires highly specific, systematic and structured methodologies with supporting materials; common suggestions about comprehensive reforms, on the other hand, are less significant. Introducing elements of constructivist pedagogy combined with specific steps aimed at fostering higher-order thinking into class could be a realistic aim for teachers. Yerushalmi and Eylon (2001), for example, describe a program for teachers' professional development that focused on the question of "How can we promote self-monitoring by students in physics problem-solving?" The program stressed the use of strategies to guide students' problem-solving and consisted of problem-solving steps ranging from qualitative to quantitative.

The current study confirms Zohar's (2006) claim that teachers know very little about meta-strategic knowledge on fostering thinking in the classroom. This author emphasizes that it is not enough to apply a specific higher-level instruction, but rather the teachers must recognize matters such as what higher-order thinking skills are and how to develop them in teaching science.

The four-stage model to infuse the teaching of thinking by teaching a common content (Swartz and Parks, 1994) presented earlier (Figure 1) can be very useful in this discussion. According to this model, in order to foster students' thinking skills by teaching a specific content, a teacher needs to: Introduce a specific teaching-learning strategy applied in the class to the students; Engage them significantly in learning in the suggested way; Encourage them to Reflect on their learning; and Teach them how to Transfer the problem- 
solving approach they have experienced to other related contexts. Similarly, Blank (2000) proposed a model of critical thinking in science called the Metacognitive Learning Cycle (MLC), which emphasizes the systematic use of discussions and reflection to promote explicit metacognitive understanding of critical thinking and problem-solving. The MLC consists of four interrelated steps, which include the concepts of Introduction, Application, Assessment and Exploration.

We summarize this paper by noting two examples of approaches to foster thinking in the science class to emphasize that the notion of reforming science education must be translated into well-defined instructional strategies that teachers can infuse into teaching the common curriculum.

\section{REFERENCES}

American Association for the Advancement of Science. (1994). Science for all Americans (New York: Oxford University Press).

Angell, C., Guttersrud, Ø., Henriksen, E. K. \& Isnes, A. (2004). Physics: Frightful, but fun. Pupils' and teachers' views of physics and physics teaching. Science Education, 5(88), 683-706.

Beyer, B. (1988). Developing a scope and sequence for thinking skills instruction. Education Leadership, 45(7) 2630.

Blank, L. M. (2000). A metacognitive learning cycle: A better warranty for student understanding. Science Education, 84(4), 486-506.

Brickhouse, N.W. (1990) Teachers' beliefs about the nature of science and their relationship to classroom practice. Journal of Teacher Education, 41, 53-62.

Bybee, R. W. (1993). Reforming science education: Social perspectives and personal reflections (New York: Teachers College Press).

Costa, A. L. (1985), How can we recognize improved student thinking? (In: A. L. Costa (Ed.), Developing minds: a resource book for teaching thinking (pp 288-290). (Alexandria, VA: Association for Supervision and Curriculum Development).

Costa, A. L. (2002). Components of a dell developed thinking kills program. New Horizons for Learning. Retrieved January 3, 2007, from http://www.newhorizons.org/strategies/thinking/costa 2.htm

Dancy, M. \& Henderson, C. (2007). A Framework for articulating instructional practices and conceptions. Physical Review Special Topics: Physics Education Research, 3(1), 010103.

Dancy, M., \& Henderson, C. (2005). Beyond the individual instructor: Systemic constraints in the implementation of research-informed practices. (In: S. Franklin, J. Marx \& P. Heron (Eds.), Proceedings of the 2004 Physics Education Research Conference: American Institute of Physic).

Fontana, A. \& Frey, J. H. (2000). The interview: from structured questions to negotiated text. (In: N. K. Denzin \& Y. S. Lincoln (Eds.), Handbook of qualitative research (pp. 645-673) (2nd ed.). Thousands Oaks, CA: Sage Publications).

Fullan, M. (1993). Change forces: Probing the depths of educational reform (London: Falmer Press).

Glaser, R. E. (1984). Education and thinking: The role of knowledge. American Psychologist, 39, 93-104.

Henderson, C., \& Dancy, M. (2005). Teaching, learning and physics education research: Views of mainstream physics professors. (In: S. Franklin, J. Marx \& P. Heron (Eds.), Proceedings of the 2004 Physics Education Research Conference: American Institute of Physics).

Hofstein, A., Carmeli, M. \& Shore, R. (2004). The professional development of high school chemistry coordinators. Journal of Science Teacher Education, 15(1), 34.

Hollon, R. E., Anderson, C. W., \& Roth, K. J. (1991). Science teachers' conceptions of teaching and learning. (In: J. Brophy (Ed.), Advances in research on teaching (vol 2) (pp. 145-186). Greenwich, CT: JAI Press).

Huberman, M. (1989). The professional life cycle of teachers. Teachers College Record, 91(1), 31-57.

Kagan, D. M. (1992). Implication of research on teacher belief. Educational Psychologist, 27(10), 65-70.

Leou, M., Abder, P., Riordan, M. \& Zoller, U. (2006). Using 'HOCS-centered learning' as a pathway to promote science teachers' metacognitive development. Research in Science Education, 36(1-2) 69-84.

National Research Council (NRC) (1996). National science education standards (Washington, DC: National Academy Press).

National Science Teachers Association (NSTA) (2003). Standards for Science Teacher Preparation. Retrieved: January 1, $2007 \quad$ from http://www.nsta.org/main/pdfs/NSTAstandards2003.p df

Osbourne, J., Driver, R. \& Simon, S. (1998). Attitudes to science: issues and concerns. School Science Review, 79(288), 27-33.

Pajares, F. (1992). Teachers' beliefs and educational research: Cleaning up a messy construct. Review of Educational Research, 62(3), 307-332.

Patton, M. Q. (1990). Qualitative evaluation and research methods (2nd ed.) (Newbury Park, CA: Sage).

Pogrow, S. (1988). Teaching thinking to at-risk elementary students. Educational Leadership, 45, 79-85.

Pogrow, S. (1996). Reforming the wannabe reformers: Why education reforms almost always end up making things worse, Phi Delta Kappan, 77(10), 656-663.

Resnick, L. B. (1987). Education and learning to think (Washington DC: National Academy Press).

Richardson, V. (1996). The role of attitudes and beliefs in learning to teach. (In: J. Sikula (Ed.), Handbook of research on teacher education (pp.102 - 119). New York: Macmillan).

Schraw, G., Crippen, K. J, \& Hartley, K. (2006). Promoting self-regulation in science education: Metacognition as part of a broader perspective on learning. Research in Science Education, 36(1-2), 111-139.

Silverman, D. (1993). Interpreting qualitative data: Methods for analyzing talk, text and interaction (London: Sage Publications). 
Silverman, D. (Ed.) (1997). Qualitative research (London: Sage Publications).

Sternberg, R. J. (1987) Questions and answers about the nature and teaching of thinking skills. (In: J. Baron \& R. J. Sternberg (Eds.), Teaching thinking skills: theory and practice (pp.252-259). New York: Freeman).

Strauss, A. (1987). Qualitative analysis for social scientists (New York: Cambridge University Press).

Swartz, R. J. (2001). Infusing the teaching of thinking into content instruction. (In: A. L. Costa (Ed.), Developing minds: A Resource book for teaching thinking, (3rd edition). Alexandria, Virginia: Association for Supervision and Curriculum Development).

Swartz, R. J. \& Parks, S. (1994). Infusing the teaching of critical and creative thinking into content instruction (Pacific Grove, CA: Critical Thinking Books \& Software).

Van Heuvelen, A. (1991). Learning to think like a physicist: A review of research-based instructional strategies. American Journal of Physics, 59, 891-897.

Woolnough, B. E. (1994). Why students choose physics, or reject it. Physics Education, 29(5), 368- 374.

Yerushalmi Y. \& Eylon, B. (2001). Teachers' approaches to promoting self-monitoring in physics problem solving by their students. Proceedings of the International GIREP conference on physics teacher education beyond 2000, Barcelona.

Yerushalmi, E. \& Eylon, B. S. (2004). Assessing reflection on practice: a problem solving perspective. American Institute of Physics (AIP) Conference Proceedings, September 9.

Zohar A. (1999). Teachers`metacognitive knowledge and the instruction of higher-order thinking. Teaching and Teacher Education, 15, 413-429.

Zohar A. (2004a). Elements of teachers' pedagogical knowledge regarding instruction of higher-order thinking. Journal of Science Teacher Education, 15(4), 293312.

Zohar, A. (2004b). Higher-order thinking in science classrooms: Student's learning and teachers' professional development (Dordrecht: Kluwer).

Zohar, A (2006). The nature and development of teachers' metastrategic knowledge in the context of teaching higher-order thinking. The Journal of the Learning Sciences, 15(3), 331-377.

Zohar, A. \& Dori, Y. (2003). Higher-order thinking skills and low-achieving students: Are they mutually exclusive? The Journal of the Learning Sciences, 12(2) 145-181.

Zoller, U. (1997). Higher and lower-order cognitive skills: The case of chemistry. Research in Science Education, 27(1), 117130.

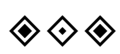

